\title{
From Access Management System (AMS) to a Ubiquitous Access Management System (UbAMS), over Federated Access Management System (FAMS)
}

\author{
Sara Jeza Alotaibi ${ }^{\# 1}$, Dr. Mike Wald ${ }^{\# 2}$, Dr. David Argles ${ }^{\# 3}$ \\ \#Learning Societies Laboratory, University of Southampton \\ University Road, Southampton SO17 1BJ, UK \\ ${ }^{1}$ sja2g09esoton.ac.uk \\ ${ }^{2}$ mwesoton.ac.uk \\ ${ }^{3}$ daesoton.ac.uk
}

\begin{abstract}
The increasing needs for updated information and collaborations around the world initiates the need to integrate Access Management Systems (AMS) with each other. The integration of AMS developed the concept of Federated Access Management Systems (FAMS). However, even this development was not able to cease the need for maintaining multiple accounts; it could only reduce the need. Moreover, the existing AMS and FAMS do not provide the security and privacy desired; these systems tend to have trust, identification and biased services issues related to them. Along with these performance issues, a lack of personalisation, usability and accessibility issues also reside. Furthermore, following extensive analysis of the current systems, a new term has been invented for an innovative system which will address all the limitations and constraints of AMS and FAMS-Ubiquitous Access Management Systems (UbAMS). UbAMS will provide users with access to their web accounts and services from any access management system, rather than providing access to a specific set of systems. It will also provide personalisation features, alongside compliance with accessibility and usability standards.
\end{abstract}

Keywords - Access Management System, Federated Access Management System, Ubiquitous Access Management System

\section{INTRODUCTION}

The modern world is highly competitive in terms of being equipped with the latest information and technology. The advent of the Internet further fuelled this desire, since it has provided avenues of being connected to the world. Different services started being offered on the web which has created the need for the users to create online accounts, which requires the entry of personal information and details. Another aspect which has threatened information revolves around the fact that organisations made their customers' data available on the internet so that their services could be available online; however, the availability of an ocean of knowledge and personal information tempted malicious users to utilise such personal data for criminal purposes, and different techniques were invented to threaten the privacy of the users.

The violation of user privacy created a daunting need for rights management systems which would be able to filter the users [1, 2]. Access management systems provided access rights for a specific system only to the users whose identity could be verified by the system [3, 4]. This was a major improvement with respect to the issue of security breaches of personal details and identity attributes. However, access management systems at this time lacked in the area of providing unified access across several systems; these systems provided identity management to single systems or organisations [5-10]. The constraint of limited access and the maintenance of multiple accounts for accessing different organisations did not meet the highly competitive needs of the modern world. Therefore, federated access management systems were created with the aim of providing access to several systems and organisations through a unified identity [11-14]. Importantly, federated access management systems reduced the need to maintain several accounts, and also facilitated the tracking of the data revealed on the web. Notably, it is very common for individuals to forget the information that is given at the time of registration for different accounts and services. Federated access management systems provide a single domain for the provision of access to several accounts; therefore, information was maintained only on a single source.

The increasing needs for updated information and collaborations around the world initiates the need to integrate access management systems with each other. For this, we began with an AMS which has been explained in Section II. The integration of the access management system developed the concept of federated access management systems, as has been described in Section III. However, even this development was not able to cease the need for the maintenance of multiple accounts; it could only reduce the need. Therefore, a new access management system has been proposed, as outlined in Section $V$, which might integrate all the federated access management systems with the use of a single platform so that a single identity can provide access to all accounts.

\section{Past: Access Management Systems}

With the passage of time, the need for effective security measures has become evident, and access management systems have accordingly been developed [1]. Access management systems authorised access to registered members on the basis of their identity attributes [3]. The management of 
credentials and information was given high priority, and information was exchanged only with those sources considered reliable and authentic. This definition provided a broad concept of the respective systems, whereas another definitions, such as that by CafeSoft [4], states that they were a unified source for the management of authentication processes for individuals and the application of business rules to safeguard customer information. Business organisations and e-commerce websites are usually attractive for attackers [4]; this definition includes the aspect regarding business rules, which is why it seems more comprehensive.

\section{A. Different Terms for AMS}

Table 1 summarises a critical review of theoretical information regarding different terms of Access Management Systems, and the areas of usage of such terms:

TABLE I DIFFERENT TERMS FOR AMS

\begin{tabular}{|c|c|c|}
\hline Terms & Description & Area of Usage \\
\hline $\begin{array}{l}\text { Traditional } \\
\text { Identity } \\
\text { Management } \\
\text { Model [5] }\end{array}$ & $\begin{array}{l}\text { A system that has IP+SP } \\
\text { authentication mechanism i.e. } \\
\text { Identity Provider from a specific } \\
\text { Service Provider. Each SP } \\
\text { authenticates its own IPs. Each SP } \\
\text { maintains its own list of authorised } \\
\text { accounts; therefore, users have to } \\
\text { maintain numerous accounts [6]. }\end{array}$ & $\begin{array}{l}\text { - E-commerce } \\
\text { websites } \\
\text { - Online } \\
\text { services like e- } \\
\text { mail accounts, } \\
\text { social } \\
\text { networking } \\
\text { websites. }\end{array}$ \\
\hline $\begin{array}{c}\text { Broadband } \\
\text { Access } \\
\text { Management } \\
\text { Systems [30] }\end{array}$ & $\begin{array}{l}\text { This system comprises four types } \\
\text { of architectures, namely functional, } \\
\text { network, system and software. }\end{array}$ & $\begin{array}{l}\text { Management } \\
\text { and access } \\
\text { control } \\
\text { purposes of an } \\
\text { organisation. }\end{array}$ \\
\hline $\begin{array}{c}\text { Role and } \\
\text { Activity } \\
\text { Based } \\
\text { Access } \\
\text { Control } \\
\text { Model [29] }\end{array}$ & $\begin{array}{l}\text { This model facilitates the } \\
\text { administration of users on the basis } \\
\text { of roles. This model integrates the } \\
\text { aspect of participation and } \\
\text { activities into the system. }\end{array}$ & $\begin{array}{l}\text { Used as a } \\
\text { university } \\
\text { access control } \\
\text { management } \\
\text { system. }\end{array}$ \\
\hline $\begin{array}{c}\text { Site Access } \\
\text { Management } \\
\text { Systems } \\
\text { (SAMS) [23] }\end{array}$ & $\begin{array}{l}\text { This system manages the access of } \\
\text { the users on a certain website. The } \\
\text { access of the users is differentiated } \\
\text { with respect to their status: for } \\
\text { example, some data will be } \\
\text { intended for registered users, } \\
\text { whereas some will be available for } \\
\text { free to general users. }\end{array}$ & $\begin{array}{l}\text { Management of } \\
\text { visitors on a } \\
\text { website. }\end{array}$ \\
\hline
\end{tabular}

Many limitations have been experienced with the access management systems; for instance, organisational access rather than a broader perspective. This has compelled users to create different accounts for different organisations [4], [28]. With this in mind, the maintenance of numerous accounts can become very tedious for users, who end up using the accounts less frequently. The less usage of such accounts leads to losses for the organisations; therefore, all these reasons accumulate so as to highlight the need for a new system which may provide access to numerous organisations with single sign-in details.

\section{Present: Federated ACCESS MANAGEMENT Systems}

As stated previously, AMS had a major constraint of limiting the access to the resources present within the vicinity of an organisation. The demanding needs for updated information in the fields of business, technology and medicine etc. raises the need to share information amongst other organisations [27]. Owing to such requirements, federated access management systems have been developed which offer access across different organisations and provide convenience through a single sign-in service [25], [23]. Importantly, every system in the federated network behaves like a node in the wider access management system: every system manages the data that resides in it; private data is handled such that no other user can access it, and semi-private data is managed such that only authorised users can access it [22]. However, this definition does not specify the owner of the authority regarding the content in the dispersed systems.

\section{A. Different Terms for FAMS}

Table II below shows a significant review of academic information concerning various different terms of Federated Access Management System and the areas of the usage of such terms:

\begin{tabular}{|c|c|c|}
\hline Terms & Description & Where to use it \\
\hline 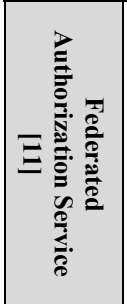 & $\begin{array}{l}\text { This service provides access to } \\
\text { learning objects repositories that } \\
\text { might be maintained in different } \\
\text { organisations. It provides } \\
\text { uniformed access to the data that } \\
\text { might be protected by different } \\
\text { authorisation protocols. }\end{array}$ & $\begin{array}{l}\text { E-learning: a collection of } \\
\text { data that is termed as } \\
\text { learning objects; can be } \\
\text { accessed by learners as } \\
\text { well as teachers. } \\
\text { Organisations: Can be } \\
\text { used in an organisation } \\
\text { for the exchange of } \\
\text { information between the } \\
\text { colleagues. }\end{array}$ \\
\hline 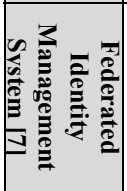 & $\begin{array}{l}\text { This is considered to provide } \\
\text { broad administrative functions } \\
\text { involving users' access rights and } \\
\text { resource utilisation limitations, } \\
\text { etc. within an organisation with } \\
\text { the utilisation of local federations. }\end{array}$ & $\begin{array}{llr}\text { Dissemination } & \text { of } \\
\text { information } & \text { and } & \text { access } \\
\text { control } & \text { in } & \text { an } \\
\text { organisation. } & & \end{array}$ \\
\hline 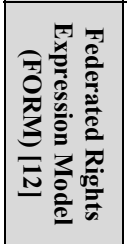 & $\begin{array}{l}\text { FORM provides access to content } \\
\text { that might be spread across } \\
\text { different organisations. It also } \\
\text { provides the rights to content } \\
\text { providers and identities providers } \\
\text { to give out licenses for the nature } \\
\text { of usage of their provided content } \\
\text { or objects. }\end{array}$ & $\begin{array}{l}\text { Online Music Magazine, } \\
\text { where users can access } \\
\text { their favourite music. }\end{array}$ \\
\hline 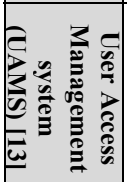 & $\begin{array}{l}\text { UAMS is defined as the system } \\
\text { component that serves as an } \\
\text { interface for the end-users for } \\
\text { applications that might be residing } \\
\text { locally or remotely. }\end{array}$ & $\begin{array}{l}\text { Organisation of various } \\
\text { applications across } \\
\text { different organisations. }\end{array}$ \\
\hline 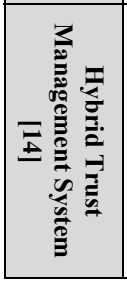 & $\begin{array}{l}\text { The roles and access to the system } \\
\text { are defined on the basis of the } \\
\text { history of the user. If the user has } \\
\text { had a good history with the } \\
\text { system with no malicious usage } \\
\text { on record then he will be } \\
\text { considered a more reliable user. } \\
\text { Reliable users will have the } \\
\text { privilege to access sensitive data. }\end{array}$ & $\begin{array}{l}\text { Used by armed forces } \\
\text { institutions to } \\
\text { differentiate the level of } \\
\text { access to their sensitive } \\
\text { data. }\end{array}$ \\
\hline
\end{tabular}

\section{B. Existing Systems}

The FAMS has been an area of attention for a few years for various different organisations. Accordingly, many 
systems have been developed, all of which have various different types of protocols, some of which have been analysed in Table III:

TABLE III EXISTING SYSTEMS FOR FAMS

\begin{tabular}{|c|c|c|}
\hline & Description of Protocols & $\begin{array}{l}\text { Example of the applications using } \\
\text { these protocols }\end{array}$ \\
\hline 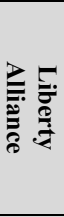 & $\begin{array}{l}\text { Users are authenticated on } \\
\text { the basis of pseudonyms; this } \\
\text { authentication attribute does } \\
\text { not contain any user- } \\
\text { identifying information and, } \\
\text { as such, it can therefore be } \\
\text { considered safer [17], [26]. }\end{array}$ & $\begin{array}{l}\text { Liberty Alliance Project Provides a } \\
\text { platform for the users to perform } \\
\text { their online transactions in a secure } \\
\text { manner. The identities of the users } \\
\text { are federated therefore greater } \\
\text { access can be achieved [19]. }\end{array}$ \\
\hline$\underset{2}{2}$ & $\begin{array}{l}\text { It is a platform independent } \\
\text { framework that is utilised to } \\
\text { transfer access-approval and } \\
\text { authentication information } \\
\text { [21]. It is limited to } \\
\text { performing authorisation } \\
\text { commands [20], [24]. }\end{array}$ & $\begin{array}{l}\text { Shibboleth is an open source } \\
\text { website that provides the facility of } \\
\text { single sign-in service to the } \\
\text { customers [9], [7]. It offers access } \\
\text { to the internal as well as external } \\
\text { content of the organisation [18]. }\end{array}$ \\
\hline 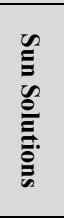 & $\begin{array}{l}\text { Sun Solutions provides } \\
\text { compatibility and flexibility } \\
\text { with multiple protocols, } \\
\text { thereby reducing the need to } \\
\text { use numerous protocols for } \\
\text { federated identity [8]. }\end{array}$ & $\begin{array}{l}\text { OpenSSO offers single sign-in } \\
\text { service across different domains to } \\
\text { save the user from the trouble of } \\
\text { resetting forgotten passwords that } \\
\text { proves to be a tedious process for } \\
\text { the organisation if many users } \\
\text { initiate it [8]. }\end{array}$ \\
\hline 율 & $\begin{array}{l}\text { OpenID protocol offers } \\
\text { simplicity and convenience } \\
\text { in the deployment of the } \\
\text { federated identity service [8]. }\end{array}$ & $\begin{array}{l}\text { - OpenID is a single sign-in } \\
\text { service for the maintenance of } \\
\text { multiple accounts. It provides } \\
\text { the service of even registering } \\
\text { at any website with the } \\
\text { credentials provided at OpenID, } \\
\text { on user's request. } \\
\text { - FingerID 1 also offers the } \\
\text { maintenance of multiple } \\
\text { accounts and a viewing facility } \\
\text { on a single platform. However, } \\
\text { FingerID offers greater } \\
\text { accessibility and convenience } \\
\text { owing to fingerprint } \\
\text { recognition and user-friendly } \\
\text { displays, respectively. }\end{array}$ \\
\hline
\end{tabular}

\section{Current Issues}

With the passage of time, the limitations with the federated access management systems began being acknowledged and recognised. For example, the federated access management systems do not offer federated access to all systems and services; on the contrary, they provide access to only a set of organisations which have agreed to collaborate with each other. Therefore, the concept of unified access is not catered to by the federated access management systems. Essentially, there are certain criteria that should be met by federated access management systems and which shall be discussed in the following sections [15]; these criteria are not met by various federated access management systems since the information of the customers might be transferred through some unreliable intermediate sources, and subsequently revealed to third parties, etc.

Many important FAMs are not able to collaborate and provide unified access to other systems; for example, OpenID

\footnotetext{
${ }^{1}$ Details can be found at $:<\underline{w w w}$.fingerid.me $>$
}

users cannot access Microsoft Passports with their OpenID account. This proves to be contradictory to the claim of federated access management system, since they do not provide unified access to all systems and organisations. A complete federated access management system should be able to provide access to all the users, irrespective of their accounts' origin. In the same vein, access management systems should be able to cater to the different needs of their customers. With this in mind, any user should be able to use the system and gain access to any service via an accessible and usable interface.

Some other issues which are prevailing in the field of federated access management systems are those systems that do not offer different languages, consequently resulting in people of other origins and cultures remaining deprived of the revolutionary services. Importantly, neither do these systems provide compatibility with assistive technologies which would make the services accessible to users with disabilities; these systems do not even comply with the usability standards to make them usable for the great majority of users.

\section{Analysis of FAMS}

The federated access management systems are evaluated with respect to various different criteria; the major classifications of the criteria are the different factors of Federated Access Management Systems (FAMS) and Accessibility/Usability aspects of the system. Figure 1 below shows the classification of the criteria:

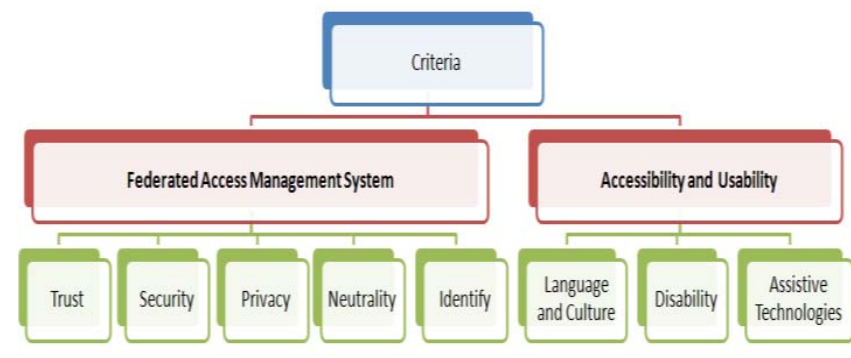

Figure 1. Classification of the criteria

As stated earlier, the criteria of analysing the effectiveness of a federated access management system includes various different factors, as highlighted below.

\section{- $\quad \operatorname{Trust}(T)$}

American Heritage defines the term 'trust' as the "confidence in terms of the integrity and capability of a thing or person" [36]. Customers trust the access management system to safeguard their data; accordingly, the data has to be protected to the extent that it should not even be forwarded via an unreliable intermediate source. The trust implications are more easily deployed if the access management system provides access to a single organisation or system rather than multiple sources [15]. Importantly, trust is one of the critical of criteria for any service, since the user will be revealing his personal information to the respective source. 


\section{- $\operatorname{Security}(S)$}

The term 'security' can be defined as the "freedom of danger or risk of any sort" [36]; therefore, only authorised parties are permitted access to the data in order to enforce security in AMS. Several techniques may be used to ensure that security is provided to the customer's data: for example, biometric authentication, security electronic tokens, encryption algorithms, etc. [16]. Moreover, security plays a fundamental role in the acceptance of an AMS by users; if the service does not provide security to its users, the sole purpose of the system is then futile.

\section{- $\operatorname{Privacy}(P)$}

Privacy can be defined as the right of the individual to keep his possessions or data safe from others [35]. In this regards, users enter different forms of information in the access management systems, such as email addresses, login credentials for web accounts, etc. Notably, it is the responsibility of the access management system to ensure that this information is not exposed to any third party [15]. Without doubt, privacy is selected as a criterion owing to the fact that the credentials of one user should never to be exposed to any other user or any third party. Accordingly, the safeguarding of the individual's privacy is one of the most important aspects of an AMS.

\section{- $\quad \operatorname{Neutrality}(N)$}

Neutrality can be defined as the instance when no sides are being supported; rather, an equal amount of share is given to all [36]. All systems and organisations should be dealt according to the same scale, and no service or organisation should be given greater priority in terms of the utilisation of resources. It would not be justified to provide greater resources or better terms of service to one organisation. Neutrality should be present in a system to ensure the user that all of his web accounts can be accessed without any bias from the provider.

\section{- $\quad$ Identity ( I)}

Identity is defined as the "collective aspect of something by which it can be recognised" [36]. The credentials should be able to identify the individuals in a reliable and effective manner. Moreover, such credentials should be assigned uniquely to individuals in order to facilitate perfect identification results. It is important for a user to be identified on the basis of unique and confidential credentials, and so this is chosen as a fundamental criterion.

\section{- Languages (L) and Culture (C)}

Culture is defined as the "beliefs, values, and customs and material traits of a religious, social or racial group" [34]. The latest trend in online services is to offer personalisation of the service in such a way so as to suit and accommodate the needs of the user. Access management systems therefore need to introduce this element into their services so that a greater range of users are able, and inclined, to utilise the service; this can be achieved through various different means, such as, for example, language options, display settings, customised pages, etc. Importantly, every culture has different views and opinions owing, and so developing trust is a very important role [33]. With this in mind, researchers conclude that people from various different cultures tend to trust different forms of technology: for example, some people associated with a specific culture might not rely upon biometric security or might not rely upon the platform of e-learning to gain knowledge [31,32]. Moreover, culture is also related to the focus and sensitivity towards people with disabilities; hence, their needs. The provision of choosing aspects with respect to culture will make people more comfortable with the service as there are various different inhibitions held by people from different cultures: for example, some cultures have a greater concern regarding privacy on the web, whilst some are not too worried about this factor.

Obviously, language can be a barrier for many users if some services do not offer language options from which to choose; therefore, language specification has been chosen as a criterion for an effective AMS. Culture preference is an important yet neglected field requiring much attention in the field of computing. Culture and its legal issues tend to affect the choices that people make and their likes or dislikes; therefore, different cultural options should be offered to the user in order to ensure convenience. It is due to this reason that culture has also been chosen as a criterion.

\section{- $\quad$ Disabilities (D)}

Disabilities are defined as "impairments that might hinder someone's routine activities" [36]. Nowadays, many different types of users are found on the internet; this might even include people with disabilities, such as weak sightedness, blindness, deafness, etc. This criterion will evaluate the degree of features available for people with disabilities.

\section{- $\quad$ Assistive Technologies (AT)}

Assistive technology is defined as "a technology that might facilitate the operation of a computer or some other technology" [36]. This factor will evaluate whether or not the access management system offers any degree of compatibility with assistive technologies.

\section{E. Evaluation of FAMS}

A critical review of an extensive evaluation of existing FAMS with different criteria that are discussed in the previous sections will be presented in the Conference.

\section{FutURE OF ACCESS MANAGEMENT SySTEMS}

The federated access management systems claim to provide access over numerous sources and give the facility of single sign-in. Although there exists a limitation amongst these applications and systems, the user still has to maintain various different identities for every federated system: for example, an OpenID account and identity will not work for Shibboleth services. Furthermore, different applications offer different services; as such, the user might make accounts on multiple systems. This will again raise the need to remember 
multiple passwords. It can be stated that there is no single sign-in service or federated access across all federated access management systems. The federated access management systems provide access to their respective specific set of domains; therefore, the user will create different accounts in order to gain access to the domains which are not accessible by a certain federated access management system [9]. Other aspects of federated access management systems which constrain its usage include the lack of usability and accessibility features in most of the federated access management systems. The systems should not only be federated with respect to the access with different systems, but also federated with regard to the different needs of the people. Our research is being conducted in the respective field in order to overcome the limitations and constraints in the current federated access management systems.

The future of access management systems is to follow a ubiquitous approach that will perform on multi-core systems. The differentiating aspect regarding the ubiquitous systems could be that the decision-making power of the system should not be embedded within it; rather, it should be according to a standard policy to be followed by all the access management systems. The standards might induce uniformity across the systems, as well as produce effective changes whenever there are any required modifications [2], [10].

\section{Ubiquitous ACCESS MANAGEMENT SySTEMS}

Following the analysis of the existing access management systems, the need for an efficient federated access management system was considered which would do justice with its name. Therefore, a new system has been proposed with the addition of a new term to the existing name: Ubiquitous Access Management System (UbAMS).

The meaning of the term 'ubiquitous' can be defined as "being or seem to be everywhere at the same time" [37]. The concept of ubiquitous computing has attracted the attention of many researchers over the past few years. Ubiquitous computing tends to amalgamate several systems and devices at the same time for the convenience of the user, and offers greater accessibility to systems and everyday objects [2]. The same approach can be utilised so as to combine all the federated systems on one platform, which helps to avoid the maintenance of several federated systems' log-in credentials.

Ubiquitous access management systems will enhance the performance of federated access management systems and really perform the effectiveness that is expected from federated access management systems. This system will enable the users to access their accounts from any system i.e. one login identity will be sufficient to provide access to all the federated access management systems. It will prove to be a revolutionary development since the existing systems do not offer this type of unified service.

This system not only offers a single sign-in on all FAMS, but could also cater to all different needs of users, such as needs to personalise the service with respect to language, culture or disabilities, etc. Figure 2 below shows how UbAMS would be above both the types of systems; FAMS and AMS.

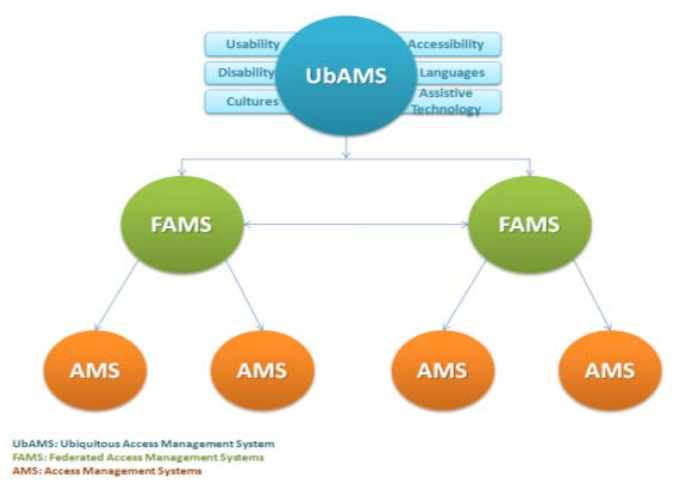

Figure. 2 Ubiquitous Access Management System (UbAMS)

\section{A. Criteria of UbAMS}

It can be seen from Figure 6 that UbAMS covers all the aspects of FAMS and AMS, as well as caters to the various different needs of the users. The features that may be offered by the respective system include:

- Culture Personalization

- Language Personalization

- Disabilities Personalization

- Support for assistive technologies

- Support for accessibility

- Support for usability

\section{B. Advantages of UbAMS}

- UbAMS might solve many prevailing issues which have been explained in this report, namely security breaches in existing systems, privacy and trust issues, bias services, or terms to different organisations, etc.

- This system could make the web experience easy for users who have disabilities, and it might also provide compatibility with assistive technology to better suit their needs.

- The compliance with usability and accessibility standards could help users to utilise all features of the service in an effective manner

\section{CONCLUSION AND FUTURE WORK}

UbAMS may prove to do justice with the concept of federated access management and accordingly provide unified access to all FAMS. They could offer different features and personalisation advantages which have not been addressed previously by any other system.

As a starting point, the FingerID System has been successfully developed, tested, and shown to be a federated access management system with a high level of security, usability and accessibility; however, UbAMS will aim to provide a comprehensive service to the users, which could be an accumulation of a diverse range of features according to the discussed criteria. UbAMS will be able to personalise the service according to the needs of the users; such needs might involve language specification, display, and level of security and privacy, etc., whereby, for example, a user who might 
reside in Saudi Arabia could change the language specification to Arabic. The system will also cater to the needs of users with disabilities, and accordingly make the entire experience of accessing the web more pleasant and convenient. The innovative aspect concerning the UbAMS will be that numerous criterion features will be present along with a genuine concept of integrating cultural preference in AMS.

Future work will focus on the development of such a revolutionary system and the development of the framework or model that will serve the purpose of the system. This model will be improved by the recommendations of people in terms of what they want from a system of its kind. The process of feedback from users will be a continuous process to produce a user-centric system. This area of research will be studied in more depth including the best way to cater for the individual needs of the users in the midst of accessing unified federated access management systems.

\section{REFERENCES}

[1] H. C. Choil, Y. H. Yi, J. H. Seo, B. N. Noh, H. H. Lee, "A Privacy Protection Model in ID Management Using Access Control", Lecture Notes In Computer Science, vol. 3481, pp. 82 - 91, 2005.

[2] R. Wilhelm, M. Maffei, "Ubiquitous Verification of Ubiquitous Systems", Lecture Notes in Computer Science, vol. 4239, pp. 73 - 81, 2006.

[3] A. Squicciarini, A. Bhargav, A. Czeskis, E. Bertino, "Traceable and Automatic Compliance of Privacy Policies in Federated Digital Identity Management", 6th Workshop on Privacy Enhancing Technologies, 2006

[4] CafeSoft, Access Management, [Online], Available: http://www.cafesoft.com/products/cams/access-management-whitepaper.html\#Introduction, 2010, [November 28, 2010]

[5] F. Pimenta, C. Teixeira, J. Pinto, "GlobaliD: Federated identity provider associated with national citizen's card", Information Systems and Technologies (CISTI), 2010 5th Iberian Conference, Spain, IEEE, 2010.

[6] A. Josang, S. Pope, "User Centric Identity Management", AusCERT Asia Pacific Information Technology Security Conference Refereed R\&D Stream, Gold Coast, Australia, 2005.

[7] K. Yamaji, T. Kataoka, M. Nakamura, T. Orawiwattanakul, N. Sonehara, "Attribute Aggregating System for Shibboleth based Access Management Federation", 2010 10th Annual International Symposium on Applications and the Internet, 2010

[8] E. Maler, "Federated Identity through the Eyes of the Deployer", Oracle Corporation, [Online], Available: http://developers.sun.com/identity/reference/techart/deployment.html, February 29, 2008, [November 28, 2010]

[9] Shibboleth, "shibboleth Web Single Sign-On and Federating Software",.internet2.edu, 2010.

[10] A.John, "Future of identity management is...now!" Identity and Access management, [Online], Available: http://go4idm.blogspot.com/2010/10/future-of-identity-management-isnow.html , 2010, [November 28, 2010]]

[11] J. Noel Colin, T. D. Le, D. Massart, "A Federated Authorization Service for Bridging Learning Object Distribution Models", Lecture Notes in Computer Science, vol. 5686, pp. 116-125, 2009

[12] T. Sans, F. Cuppens, N. C. Boulahia, "FORM: A Federated Rights Expression Model for Open DRM Frameworks", Lecture Notes In Computer Science, vol. 4435, pp. 45-59, 2007.

[13] M.J. Muller, J.S. Kaminski, G.J. Stuk, J.C. Zolnowski, A. ShHferstein, J.G. Smith, J.E. Daniel, D.T. Bartel, J.A. Wotus, G.J. Schwerdtman, "Issues in a User Access Management System", IEEE, 1988.
[14] R. Akbani, T. Korkmaz, and G.V.S. Raju, "A Hybrid Trust Management System for automated Fine-Grained Access Control", IEEE, 2009

[15] S. Melissa, "Introduction to the Federated Access Management in the UK", JISC, [Online], Available: http://www.jisc.ac.uk/whatwedo/themes/accessmanagement/federation/ about.aspx 2009, [Nov. 28, 2010]

[16] C. Lynch, "A White Paper on Authentication and Access Management Issues in Cross-organizational Use of Networked Information Resources", Coalition for Networked Information, 1998.

[17] Liberty Alliance, "Liberty Alliance Architecture Glossary", vol. 1.1, 2003.

[18] Z. A. Khattak, S. Sulaiman, L. A. Manan, "A Study on Threat Model for Federated Identities in Federated Identity Management System", IEEE, 2010.

[19] Kantara initiative, "Liberty Alliance project", [Online], Available: http://www.projectliberty.org/, 2010, [October 30, 2010]

[20] Sun Microsystems, "Sun's XACML Implementation", [Online], Available: http://sunxacml.sourceforge.net/ , July 16, 2004, [October 30 2010]

[21] OASIS, Security Services Technical Committee: OASIS. www.oasisopen.org/committees/security/, 2010.

[22] M. Wiedijk, H. Afsarmanesh, and L.O. Hertzberger, "Co-working and Management of Federated Information- Clusters", Lecture Notes In Computer Science; vol. 1134, 1996.

[23] G.A. Douglas, "Technical Considerations in Site Access Management Systems", IEEE, 2000

[24] SAML OASIS Standard, "Security Assertion Markup Language (SAML) V2.0", [Online], Available: http://saml.xml.org/samlspecifications , 2010, [October 31 2010]

[25] S. S. García, A. G. Oliva, R. Meersman, P. Herrero, T. Dillon, "Solving Identity Management and Interoperability Problems at PanEuropean Level", Lecture Notes In Computer Science, vol. 5872, pp. 805-809, 2009.

[26] Liberty Alliance, "Liberty Alliance Protocols and Schema Specification", vol. 1.2, 2002.

[27] W. Jinfei, L. Hai, "The Access Control Research of Management Information System”, IEEE, 2010.

[28] American Systems, "Identity and Access Management systems", [Online], Available: http://www.2asc.com/Services/ConsultingServices/IdentityAndAccess Management/default.htm, 2010, [October 29 2010].

[29] S. Zheng, D. Jiang, Q. Liu, "A Role and Activity Based Access Control Model for University Identity and Access Management System", 2009 Fifth International Conference on Information Assurance and Security, 2009.

[30] T.Kawagoe, H.Kawakami, K.Soga, K.Tanaka, H.Okazaki and S.Hasegawa, "On the Design and an Implementation of Broadband Access Management Systems", IEEE, 1996.

[31] S. Omosule, C. Shoniregun, D. Preston, "A Framework for Culture Influence Virtual Learning Environments Trust”, IEEE, 2008.

[32] M. A. Hamar, R. Dawson, L. Guan, "A Culture of Trust Threatens Security and Privacy in Qatar", 10th IEEE International Conference on Computer and Information Technology, 2010.

[33] P. B. Lowry, D. Zhang, L. Zhou, X. Fu, "The Impact of National Culture and Social Presence on Trust and Communication Quality within Collaborative Groups", Proceedings of the 40th Hawaii International Conference on System Sciences, 2007.

[34] SteppingStones.org, "Defining Culture", [Online], Available: http://www.steppingstonesforvets.org/Community\%20IssuesCulture/Defining_Culture.pdf, 2010, [Nov 24, 2010].

[35] A. Westin, Privacy and Freedom. Atheneum, New York, 1967.

[36] Houghton Mifflin Harcourt, "American Heritage Dictionary, Dictionary of the English Language, Fourth Edition", 2010

[37] Yahoo Education, "Ubiquitous", [Online], Available: http://education.yahoo.com/reference/dictionary/entry/ubiquitous, [Nov $18,2010]$. 